\title{
Study on Mixed Packing of Flotation Column
}

\author{
Zhang Min \\ College of Resources and Metallurgy of Guangxi \\ University \\ Nanning, China \\ scetmin@126.com \\ Shen Jiahua \\ College of Resources and Metallurgy of Guangxi \\ University \\ Nanning, China \\ 497980652@qq.com
}

\begin{abstract}
Packing in a flotation column is one way to increase separation efficiency and effective descending flotation-column height. In this paper, the two packing mode of filling packing and sieve packing is described. Based on sieve-plate packing, a high-efficiency mixed packing mode consisting of screen-plate packing and honeycomb-tube packing has been proposed, with the packing mode optimized in the cyclonic static microbubble flotation column in the separation zone. In the mixed packing mode, the honeycomb tubes are used to reduce the vortex effect at the base of the column and weaken the radial dispersion of jetting bubbles, and the sieve plates are used to comminute bubbles in the separation zone, to lengthen the bubble migration path, and to stabilize the foam layer. The superiority of honeycomb-tube packing is analyzed using bubble-particle collision theory, and the dynamic equations of collision probability are derived. The role of mixed packing in guaranteeing mineral recovery is analyzed by the axial dispersion method. When a high-turbulence flow is maintained, a static separation environment is formed.
\end{abstract}

Keywords-Column flotation; Flotation bubbles; Mineral separation; Mixed packing; Cyclone flow

\section{INTRODUCTION}

The idea of a packed flotation column[1] came from the wide use of tower equipment in chemical processes. Its main features are: 1) the fluid phase in the flotation column can be varied and controlled, and plug flow can be achieved in the flotation process; 2) the energy exchange is strengthened within the three-phase system, and the mechanisms used to encourage countercurrent collisions become effectively stabilized; 3) the foam layer is supported by filling, so that the selection processes of collision and mineralization can work efficiently; 4) the conversion of gas into bubbles is encouraged, and the bubbles merge with some difficulty into the flotation column[2].

In recent years, the filling of flotation columns has been widely studied. The flotation column is divided to create a narrow space in the axial direction. Slug flow is formed by slurry flowing from the top to the bottom and bubbles running from bottom to top. The bubble distribution in the radial direction is thus improved. In this way, merging flows, strong back mixing, and unstable

\author{
Ma Shaojian \\ College of Resources and Metallurgy of Guangxi \\ University \\ Nanning, China \\ msj3503@sina.com \\ Liu Dongyun \\ College of Resources and Metallurgy of Guangxi \\ University \\ Nanning, China \\ liudy0325@126.com
}

operation can be effectively prevented. However, filling a flotation

column has many disadvantages. For example, filling is costly, installation and maintenance workload is heavy, and anti-blinding performance is poor. Furthermore, corrugated packing is ineffective at curbing large-scale eddies in the vertical direction.

Hessel proved that sieves can prevent liquid from mingling in the radial direction and decrease bubble coalescence [3]. The sieve plates can improve the radial diffusion of bubbles and the rapid outflow of slurry along the axial direction of the column, leading to formation of slug flow as described earlier and an increase in the separation effect.

This paper has the start point of application basis of cyclonic static microbubble column flotation, the new packing media in a flotation column is proposed, and a new flotation process is formed.

\section{OptimiZATION OF FLOTATION-COLUMN PACKING}

The particular gradient-optimization separation structure of cyclonic static microbubble column flotation has been successfully applied in china-clay mineral processing. Gradient-optimization separation takes place in three stages: column flotation, cyclone separation, and pipe-flow mineralization. The distinguishing characteristics of cyclone separation are the use of the suspending liquid to perform separation and the use of a cyclone as a separation environment. According to the principle of nozzle flow, pipe-flow mineralization depends on drawing air into solution and compressing it into air bubbles. This exemplifies the three recycle flow systems along the pipe and achieves turbulence and mineralization [4].

As the cyclonic field rises and expands, lifting air bubbles and slurry in the column separation zone, the bubbles and slurry are unavoidably drawn into a circular motion, thus causing a turbulent current. The apparent contradiction between the static separation performed by column flotation and the high-turbulence current created by the liquid rotating at the bottom of the column has posed a major technical obstacle to the development of cyclonic static microbubble column flotation.

Theoretically, the greater the open area in the sieve plates, the greater will be the flotation flux. If the 
sieve-plate position is close to the cyclonic zone, recovery inside the column will be weak; on the other hand, the inhibition of radial cyclonic flow will also be weak. Therefore, the improved performance brought about by the sieve plate does not solve all operating problems.

A combination of sieve-plate and honeycomb-tube packing is therefore proposed for cyclonic static microbubble column flotation, as shown in Figure 1a and Figure 1b. The characteristics of this mixed-packing approach are that the honeycomb tubes are used to reduce vortex formation in the base of the column and weaken the radial dispersion of jetting bubbles, and the sieve plates are used to comminute bubbles in the separation zone, lengthen the migration path of the bubbles, and stabilize the foam layer.

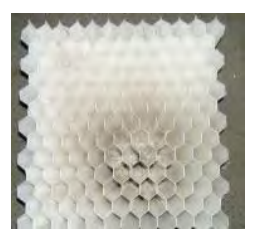

Figure 1a. overhead view

of honeycomb tube

column; c Mixed flotation column)
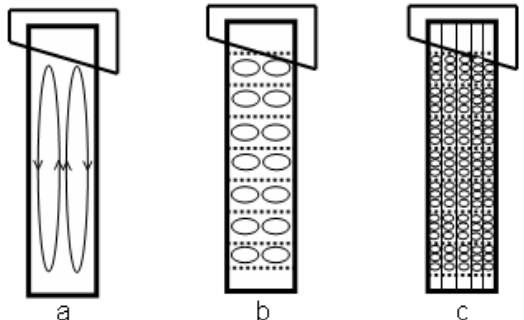

Figure 2. Comparison of packing effect in three column flotation (a :Empty flotation column; b Sieve-plate flotation column; c Mixed flotation column)

Fig .2 is the comparison of packing effect of empty flotation column, sieve plate packing flotation column, and mixed packing flotation column. The mixed packing further reduces the turbulence and back-mixing phenomenon, forms more stable gradient grade, improves selectivity, and achieves higher degree concentration in shorter cylinder.

\section{COLLISION THEORY OF MINERAL PARTICLES AND BUBBLES IN THE HONEYCOMB TUBE}

It is known from mineral separation practice that separation efficiency is higher in 50-mm-diameter column flotation than in 3-m-diameter column flotation because of radial dispersion. In this experiment, the slurry was thoroughly converted, and the mineralization effect was good, that is to say, the bubbles were vertically mineralized, the flotation effect was reinforced, the lower limit of separation was reduced, and separation efficiency was increased. The operation of the honeycomb tube will be explained using bubble theory and the ore-particle collision probability[5-9].

The theory of bubble-particle collision can be developed in various ways. The formulation proposed by Qiu et al.[10] is shown in equation (1):

$R_{e b}=\frac{2 \rho \cdot U_{b} \cdot R_{b}}{\eta} \quad P_{c}=B_{c}\left(\frac{d_{p}}{d_{b}}\right)^{n}$

(1)

Where $\mathrm{Bc}$ and $\mathrm{n}$ constant. For various fluid conditions, values of $\mathrm{Bc}$ and $\mathrm{n}$ are given in Table 1. $\mathrm{dp}$ and $\mathrm{db}$ represent mineral-particle diameter and bubble diameter respectively, Reb is the Reynolds number of the bubbles, , and $\mathrm{Ub}$ is bubble velocity.

Honeycomb packing means that the flotation column is divided into small units of limited size, and mineral particles and air bubbles are then randomly directed into the various small units. The coefficient $N_{c}$ relates to collision probability. A mineral particle or bubble can enter a cell only if the cell is small, and the collision probability is increased by a small cell volume. Therefore, the dimensionless quasi-number

is set to $N_{c}=\lambda\left(l_{f} / d_{f}\right) \phi_{f}^{-1}$, where $\lambda$ is the probability that a bubble or a mineral particle is randomly distributed into a particular honeycomb tube, $l_{f}$ and $d_{f}$ represents respectively the height and diameter of the honeycomb, and $\phi_{f}$ is the proportion of open area ${ }^{[11-13]}$.

Therefore, the dynamic equation for collision probability in a honeycomb tube

can be written as shown in equation (2):

$P_{c}=\frac{3}{2} N_{c}\left(\frac{d_{p}}{d_{b}}\right)^{2}$ 
TABLEI. VALUES OF BC AND N FOR DIFFERENT FLUID TYPES

\begin{tabular}{lcc}
\hline Fluid type & $B_{c}$ & $n$ \\
\hline Laminar & $3 / 2$ & 2 \\
Intermediate & $3 / 2+4 R_{e b}{ }^{0.72} / 15$ & \\
Flow (1) & $3 / 2^{\left[1+3 / 16^{R_{e b}} /\left(1+0.24 R_{e b}{ }^{0.56}\right)^{]}\right.}$ & \\
Intermediate & 3 & 1 \\
Flow (2) & 3 \\
Turbulence & 3 \\
\hline
\end{tabular}

TABLEII. SIEVE-PACKING SEPARATION.

\begin{tabular}{cccccc}
\hline$(\%)$ & Feed & Concentrate & Tailing & Yield & Recovery \\
\hline 1 & 0.724 & 25.15 & 0.063 & 2.63 & 91.53 \\
2 & 0.752 & 25.72 & 0.050 & 2.73 & 93.53 \\
3 & 0.672 & 24.33 & 0.060 & 2.52 & 91.30 \\
4 & 0.794 & 27.25 & 0.069 & 2.67 & 91.54 \\
5 & 0.693 & 26.72 & 0.064 & 2.36 & 90.98 \\
Arithmetic & 0.727 & 25.83 & 0.061 & 2.58 & 91.78 \\
Average & & & & & \\
\hline
\end{tabular}

TABLEIII. MIXED-PACKING SEPARATION.

\begin{tabular}{cccccc}
\hline$(\%)$ & Feed & Concentrate & Tailing & Yield & Recovery \\
\hline 1 & 0.650 & 25.08 & 0.044 & 2.48 & 95.69 \\
2 & 0.852 & 29.93 & 0.055 & 2.67 & 93.79 \\
3 & 0.720 & 29.07 & 0.056 & 2.29 & 92.46 \\
4 & 0.745 & 25.40 & 0.046 & 2.76 & 94.10 \\
5 & 0.728 & 28.69 & 0.050 & 2.37 & 93.40 \\
Arithmetic & 0.739 & 27.60 & 0.050 & 2.50 & 93.38 \\
Average & & & & & \\
\hline
\end{tabular}

Table 2 and Table 3 show respectively the results of sieve packing and mixed packing of a flotation column processing copper ore in Yunnan, China. It is clear from Tables 2 and 3 that sieve-plate packing has the potential of yielding a product of approximately $25.83 \%$ copper concentration with $91.78 \%$ recovery from a feed with a concentration of approximately $0.727 \%$. With mixed packing, the product concentration could be further increased further to $27.60 \%$ from a feed concentration of approximately $0.739 \%$ with $93.38 \%$ recovery ${ }^{[14-15]}$.

\section{CONCLUSIONS}

In this paper, a mixed-packing approach consisting of sieve-plate and honeycomb-tube packing has been presented. The characteristics of the mixed-packing approach were that the honeycomb tubes were used to reduce the vortex effect in the base of the column and weaken the radial dispersion of jetting bubbles, and the sieve plates were used to comminute bubbles in the separation zone, lengthen the bubbles' path, and stabilize the foam layer. Based on the honeycomb-tube packing model, the dynamic equation for the collision probability of air bubbles and particles was derived, which has provided a new techniques and development idea for mineral flotation technology.

\section{ACKNOWLEDGEMENT}

The authors would like to acknowledge the financial support from Project 51404076 supported by the National Youth Science Foundation of China and ZD2014005 supported 
by Guangxi Education Department of China

\section{REFERENCES}

[1] Yang, J.L. New type packed flotation column. Metallic Ore Dressing Abroad,1991,2:8-10.

[2] Liu, J.T. The separation method of cyclonic-static micro-bubble column flotation and practical application: Part 2: Stabilization and packing patterns of the separation process in the flotation column. Coal Preparation Technology, 2000, 2: 1-5.

[3] Hessel,T.C. The stability of screen plates in a flotation column. Metallic Ore Dressing Abroad, 2002 ,6:24-26.

[4] Liu, J.T. Study on cyclonic static micro-bubble column flotation and clean coal preparation, Doctor thesis. China University of Mining \& Technology (Beijing), 1998,27-36.

[5] Finch J.A., Dobby G.S, Column Flotation, Pergamon Press, 1989,17-35.

[6] Mankosa M.J, Luttrell G.H and Yoon R.H, A Study of axial mixing in column flotation, International Journal of Mineral Processing, 1992,35:51-64.

[7] Lockett, M.J., Kirkpatrick, R.D., Uddin, M.S. Froth regime point efficiency for gas film controlled mass transfer on two-dimensional sieve tray[J]. Trans.Instn. Chem.Engrs. 1979, 57(1): 25-34.

[8] Taitel, Y. and Dukler, A.E. A model for predicting flow regime transitions in horizontal gas-liquid flow[J]. AIChE.J., 1976,22: $47-55$.
[9] Levenspiel,O. Chemical Reaction Engineering, 3rd Edition, John Wiley \& Sons, New York, 1962, Chapter 9,516-539.

[10] Qiu, G.Z. Interactivity among particles and fine particle flotation [M]. Changsha (China): Central South University Press, 1993, 53-58.

[11] LIU Jiong-tian,ZHANG Min,LI Yan-feng,etc.Research on Pressure Drop Performance of the Packing-Flotation Column. Journal of China University of Mining \& Technology. 2006,16 (4) :389-392.

[12] LIU Jiong-tian, ZHANG Min, LIU Huan-bin. Velocity Field Distribution of Flotation Fluid in the Sieved-Flotation Column. Journal of China University of Mining \& Technology. 2007,36 (5) : :578-581.

[13] Zhang Min, Liu Jiongtian. Bubble Behaviors and Influencing Factors of the Sieved-Flotation Column. Journal of China University of Mining \& Technology. 2005, 34 (6) :766-769.

[14] ZHANG Min, LIU Jiong-tian,WANG Yong-tian,ZHANG Hai-jun,ZHAI Ai-feng,CAO Yi-jun.Dnamic Analysis and Optimization of Flotation-Column Packed Separation Zone. Journal of China University of Mining \& Technology. 2008, 37 (3) : $343-346$.

[15] Zhang Min, Liu Jiongtian, Wang Yongtian. The application and the effect value of the flotation column packed sieve plate. $2005,14(14): 60-62$. 